\title{
Comparison of adrenal vein control methods in laparoscopic adrenalectomy*
}

\author{
Murat Arslan, ${ }^{1}$ Altuğ Tuncel, ${ }^{2}$ Tansu Değirmenci, ${ }^{3}$ Zafer Kozacıoğlu, ${ }^{3}$ \\ Ersin Köseoğlu, ${ }^{2}$ Yılmaz Aslan, ${ }^{2}$ Cenk Gürbüz, ${ }^{4}$ Ali Atan ${ }^{2}$ \\ 'Department of Urology, Faculty of Medicine, Izmir University, Izmir, Turkey \\ ${ }^{2}$ Department of Urology, Ankara Numune Training and Research Hospital, Ankara, Turkey \\ ${ }^{3}$ Department of Urology, Bozyaka Training and Research Hospital, Izmir, Turkey \\ ${ }^{4}$ Department of Urology, Goztepe Training and Research Hospital, Istanbul, Turkey
}

\begin{abstract}
Introduction: The aim of the present study was to compare different methods of adrenal vein control in patients undergoing laparoscopic adrenalectomy.

Materials and Methods: Total of 87 patients who underwent laparoscopic adrenalectomy (transperitoneal, $n=61$; retroperitoneal, $n=26$ ) due to adrenal mass were included in this study. Mean age was 50.9 years. In 57 patients (65.5\%), adrenal vein was controlled using Hem-o-lok (Teleflex, Inc., Wayne, PA, USA) ligation clip, and in remainder $(n=30 ; 34.5 \%)$, adrenal vein was controlled using LigaSure (Medtronic, Inc., Minneapolis, MN, USA) vessel sealing system (Group 2).

Results: Mean age of the patients in Group 1 and Group 2 was $52.7 \pm 4.5$ years and $54.4 \pm 4.0$ years, respectively ( $p=0.264)$. Mean diameter of lesion was $42.7 \pm 2.2 \mathrm{~mm}$ (range: $21-87 \mathrm{~mm}$ ) and $37.5 \pm 3.6 \mathrm{~mm}$ (range: 15 $72 \mathrm{~mm}$ ) in Group 1 and 2, respectively ( $<<0.001$ ). Mean operating time was $97.5 \pm 5.8$ minutes (range: $60-126$ minutes) and $90.2 \pm 4.6$ minutes (range: $50-150$ minutes) in Group 1 and 2 , respectively $(p=0.001)$. Mean estimated blood loss was $100 \mathrm{~mL}$ (range: $20-350 \mathrm{~mL}$ ) and $5 \mathrm{~mL}$ (range: $0-10 \mathrm{~mL}$ ) in Group 1 and 2, respectively $(p<0.001)$. Mean length of postoperative hospitalization was $4.9 \pm 4.2$ days (range: $1-13$ days) and $2.9 \pm 1.8$ days (range: 1-9 days) in Group 1 and 2, respectively $(\mathrm{p}=0.029)$. Intraoperative complication occurred in 3 patients (5.2\%) (adrenal vein avulsion) and 1 patient (3.3\%) (spleen laceration) in Group 1 and 2, respectively.

Conclusion: LigaSure vessel sealing system had lower complication rate compared with Hem-o-lok ligation clip during laparoscopic adrenalectomy.

Keywords: Adrenal; hemostasis; instrumentation; laparoscopy.
\end{abstract}

\section{Introduction}

Laparoscopic adrenalectomy (LA) is one of the successful interventions of minimally invasive surgery techniques. Since the first practice of LA in 1992, ${ }^{[1]}$ this intervention has become a standard operation in most centres. Several studies have reported that LA ensures lower complication rates, less operative blood loss, less post-operative pain, earlier return to normal life, and shorter hospitalization stay. ${ }^{[2-5]}$ With developments in energy devices such as ul- 
trasonic instruments and vessel sealing system, complex laparoscopic procedures are becoming safer, faster, and easier to accomplish. The energy devices provide a reasonable alternative to clips, sutures, and staplers, both during open and laparoscopic surgery.

In the present study, the efficiency of conventional Hemo-lok ${ }^{\circledR}$ ligation clip (Weck-Telefl ex, USA) and LigaSure ${ }^{\circledR}$ vessel sealing system (Covidien Health Care, USA) on adrenal vein control during LA is compared.

\section{Materials and Methods}

The study has been approved by the local ethics committee and valid patient consent was obtained before surgery. Between March 2007 and June 2012, a total of 87 patients (52 female, 35 male) with a mean age of 50.9 (22-74) years underwent LA (transperitoneal=61, retroperitoneal=26) due to adrenal mass. Transperitoneal and retroperitoneal procedures were performed by two of the experienced authors (AT= Transperitoneal, MA= Retroperitoenal). The surgical approach was selected upon the surgeon's experience. All patients were referred to us by Endocrinology and Metabolism Clinic and they underwent a detailed workup, including history, physical examination, and preoperative laboratory studies consisting serum cortisol, adrenocorticotropic hormone, renin, and aldesterone, 24hour urine collection for epinephrine, norepinephrine, metanephrine, normetanephrine, and vanilmandelic acid. Diagnostic radiological examinations such as computerized abdominal tomography or magnetic resonance imaging were also performed for the localization of the adrenal mass. Metaiodo-benzyl-guanidine scans were carried out in patients with suspected pheochromocytoma. Adrenal masses were on the right side in fifty-one patients (58.6\%) and on the left in 36 patients (41.4\%). The patients underwent LA via transperitoneal or retroperitoneal approach, as previously described. ${ }^{[6]}$ Surgical procedures were performed by 3 experienced laparoscopic surgeons (MA, AT, CG).

In fifty-seven (65.5\%) patients, adrenal vein was controlled using Hem-o-lok ${ }^{\circledR}$ ligation clip (Weck-Telefl ex, USA) (Group 1), whereas in others ( $n=30,34.5 \%)$, adrenal vein was controlled using LigaSure ${ }^{\circledR}$ vessel sealing system (Covidien Health Care, USA) (Group 2). There was no conversion to open surgery.

\section{Statistical Analysis}

The statistical analysis was performed by using Statisti- cal Package for Social Sciences (SPSS Inc, USA) version 13.0 for Windows. In case of normal distribution of the variables, Student's t-test for independent samples was performed; otherwise the nonparametric Mann-Whitney $\mathrm{U}$ test was used. A p value less than 0.05 was considered significant.

\section{Results}

The mean age of the patients in Groups 1 and 2 was $52.7 \pm 4.5$ and $54.4 \pm 4.0$ years, respectively $(p=0.264)$. The mean diameter of the lesion was $42.7 \pm 2.2$ (range; 21 to 87 ) and 37.5 \pm 3.6 (range; 15 to 72 ) $\mathrm{mm}$ in Groups 1 and 2, respectively $(\mathrm{p}<0.001)$. The mean operation time was $97.5 \pm 5.8$ (range; 60 to 126) and 90.2 4 4.6 (range; 50 to 150) minutes in Groups 1 and 2 ( $\mathrm{p}=0.001)$, respectively. The mean estimated blood loss was 100 (range; 20 to 350) and 5 (range; 0 to 10$) \mathrm{mL}$ in Groups 1 and 2, respectively $(\mathrm{p}<0.001)$. The mean post-operative hospitalization time was $4.9 \pm 4.2$ (range; 1 to 13 ) and 2.9 \pm 1.8 (range; 1 to 9) days in Groups 1 and 2 ( $p=0.029$ ), respectively. Indications for surgery were adenoma ( $n=43)$, pheochromocytoma ( $n=11)$, Cushing's syndrome $(n=4)$, metastasis from another organ cancer $(n=9)$, adrenocortical carcinoma $(n=7)$, paraganglioma $(n=4)$, Conn's syndrome $(n=3)$, myelolipoma $(n=3)$, adrenal pseudocyst $(n=2)$, hemangioma $(n=1)$. Post-operative final histopathological results are summarized in Table 1 with regard to the groups.

According to modified Clavien classification, Grade IV complications occurred in 3 (5.2\%) (adrenal vein avulsion=3) and $1(3.3 \%)$ (spleen laceration=1) patients in Groups 1 and 2, respectively. In Group 1, all adrenal vein avulsions occurred in retroperitoneal approach. In two of

Table 1. Post-operative final histopathological results

\begin{tabular}{lcc} 
Histopathology & Group 1 & Group 2 \\
\hline Adenoma & 29 & 14 \\
Pheochromocytoma & 3 & 8 \\
Metastasis & 7 & 2 \\
Adrenocortical carcinoma & 4 & 3 \\
Cushing's syndrome & 3 & 1 \\
Paraganglioma & 3 & 1 \\
Conn's syndrome & 3 & - \\
Myelolipoma & 2 & 1 \\
Pseudocsyt & 2 & - \\
Hemangioma & 1 & - \\
\end{tabular}


these patients, the adrenal vein avulsion took place due to improper Hem-o-lok ${ }^{\circledR}$ clip placement caused by adherent tissue. In the remaining one patient, the notched tip of the clip lacerated the vessel wall. In Group 2, spleen laceration occurred in transperitoneal approach during posterior dissection of the adrenal gland. All surgical complications were successfully fixed laparoscopically.

\section{Discussion}

LA has several advantages over open surgery and it is now supported worldwide. Although laparoscopic surgery has proven to be a relatively safe procedure, modern technology has provided the opportunity to develop improved equipments so as to decrease costs, and improve efficiency. One of the more recent developments in laparoscopic surgery has focused on vessel sealing equipments utilizing alternative energy sources. Laparoscopic vessel sealing devices have revolutionized modern laparoscopy and they fall into two major categories: advanced bipolar and ultrasonic instruments. ${ }^{[7,8]}$ The LigaSure ${ }^{\circledR}$ vessel sealing system is a unique bipolar energy system that seals vessels up to $7 \mathrm{~mm}$ in diameter. The sealing procedure is under the control of a feedback device and stops when the vessel gets completely sealed off. ${ }^{[7]}$ The LigaSure ${ }^{\circledR}$ vessel sealing system has shown to have shorter dissection time, better seal quality time, lesser blood loss, fewer conversion rates. ${ }^{[8-10]}$ Moreover, the device claims to measure temperature or impedance to provide consistent heating in order to prevent injuries. ${ }^{[1]} \mathrm{A}$ study has revealed the sealing procedure to be as reliable as clips or ligatures. ${ }^{[12]}$ With the LigaSure ${ }^{\circledR}$ vessel sealing system, precise dissection and exposure of the adrenal vein are not necessary, and after the vessels are sealed and cut, bleeding during manipulation of the adrenal vein is no longer a possibility. ${ }^{[13]}$

During standard LA, control of the adrenal vein requires gentile dissection and isolation before clips can be used. During this procedure, the fragile adrenal veins may get injured and lead to massive bleeding. When serious bleeding develops, the conversion to open surgery is mandatory. In addition, there is always a risk of not placing the clips properly, resulting in a loss of control of bleeding from the adrenal vein.

In the international literature, the use of the LigaSure ${ }^{\circledR}$ vessel sealing system during LA has been described in 3 studies. In a study by Yavuz, twenty-three laparoscopic transperitoneal adrenalectomies were performed in 22 patients using the LigaSure ${ }^{\circledR}$ vessel sealing system. ${ }^{[14]}$
Indications for surgery were non-functioning adenoma $(\mathrm{n}=10)$, pheochromocytoma $(\mathrm{n}=4)$, Cushing's syndrome $(n=5)$, Conn's syndrome $(n=2)$, and lymphoma $(n=1)$. The mean diameter of lesions was $40 \mathrm{~mm}$. The distribution was 12 left, 9 right, and one bilateral adrenalectomies. The mean operation time for unilateral adrenalectomies was 57 minutes. The operation time for the patient with Cushing's disease in whom a bilateral adrenalectomy was performed was 180 minutes. All operations were completed laparoscopically without any mortality. The author concluded that vascular control and dissection of the adrenal gland by LigaSure ${ }^{\circledR}$ vessel sealing system was feasible and it made the procedure easier and eventually shortened the operation time during LA. In a study by Misra et al., ten patients with adrenal tumors and 4 with extra-adrenal tumors were operated on laparoscopically using LigaSure ${ }^{\circledR}$ vessel sealing device. ${ }^{[13]}$ The mean size of the tumor was $62 \mathrm{~mm}$. The mean operation time and blood loss were 123 minutes and $70 \mathrm{~mL}$, respectively. Histopathology revealed pheochromocytomas in 7 patients. The authors reported that none of the patients experienced any major intraoperative or postoperative bleeding. They concluded that the use of LigaSure ${ }^{\circledR}$ vessel sealing device during LA was safe and effective. In a recent study by Surgit, the LigaSure ${ }^{\circledR}$ device was used in thirty-two patients undergoing LA for adrenal masses. ${ }^{[15]}$ Adrenal masses had a mean greatest diameter at $34 \mathrm{~mm}$. Mean operation time and blood loss were 83 minutes and $36 \mathrm{~mL}$, respectively. No patients experienced major bleeding intra-operatively and post-operatively. Adrenal tumor types included adrenocortical adenoma (16 patients), pheochromocytoma (13 patients), malignant pheochromocytoma (1 patient), chromophobic carcinoma (1 patient), and metastasis from a renal cell carcinoma (1 patient). The author claimed that the LigaSure ${ }^{\circledR}$ device seemed to be safe and effective in vessel closure.

In some studies, operation times in laparoscopic procedures have been presented to be shortened using LigaSure $^{\circledR}$ device. ${ }^{[16,17]}$ As mentioned above, in a series of LA in which the LigaSure ${ }^{\circledR}$ device was used the reported operation times were between 57 to 123 minutes and mean sizes of the adrenal masses were between 40 to $62 \mathrm{~mm} \cdot{ }^{[13-15]} \mathrm{In}$ the present study, the mean operation time and mean size of the adrenal masses in the LigaSure ${ }^{\circledR}$ device group were 90.2 (range; 50 to 150) minutes and 37.2 (range; 15 to 72) $\mathrm{mm}$, respectively. When considering the size of the adrenal mass, the result of present study was similar to the literature. 
In the present study, the higher operation time (mean, 97.5 minutes) in the Hem-o-lok ${ }^{\circledR}$ ligation clip group can be attributed to the adrenal vein avulsion. In the Hemo-lok ${ }^{\circledast}$ ligation clip group, higher numbers $(n=3)$ of the adrenal vein avulsion than that of the LigaSure $^{\circledR}$ device group $(n=0)$ were confronted. In two of these patients, the adrenal vein laceration occured due to improper Hem-olok $^{\circledR}$ clip placement caused by adherent tissue. In the remaining one patient, the notched tip of the clip lacerated the vessel wall. Misra et al. claimed that LigaSure ${ }^{\circledR}$ vessel sealing system was not only effective for sealing blood vessels; it could be used for dissection as well. ${ }^{[13]}$

\section{References}

1. Gagner M, Lacroix A, Bolté E. Laparoscopic adrenalectomy in Cushing's syndrome and pheochromocytoma. N Engl J Med 1992;327:1033.

2. Guazzoni G, Montorsi F, Bocciardi A, Da Pozzo L, Rigatti P, Lanzi $R$, et al. Transperitoneal laparoscopic versus open adrenalectomy for benign hyperfunctioning adrenal tumors: a comparative study. J Urol 1995;153:1597-600.

3. Gagner M, Pomp A, Heniford BT, Pharand D, Lacroix A. Laparoscopic adrenalectomy: lessons learned from 100 consecutive procedures. Ann Surg 1997;226:238-46.

4. Imai T, Kikumori T, Ohiwa M, Mase T, Funahashi H. A case-controlled study of laparoscopic compared with open lateral adrenalectomy. Am J Surg 1999;178:50-3.

5. Cobb WS, Kercher KW, Sing RF, Heniford BT. Laparoscopic adrenalectomy for malignancy. Am J Surg 2005;189:405-11.

6. Hamilton BD. Laparoscopic adrenalectomy. In: Bishoff JT, Kavoussi LR. editors. Atlas of Laparoscopic Urologic Surgery. Philadelphia: Saunders; 2007: p. 214-27.

7. Smith R, Pasic R. The role of vessel sealing technologies in laparoscopic surgery. Surg Technol Int 2008;17:208-12.

8. Hubner M, Demartines N, Muller S, Dindo D, Clavien PA, Hahnloser D. Prospective randomized study of monopolar scissors, bipolar vessel sealer and ultrasonic shears in laparoscopic colorectal surgery. Br J Surg 2008;95:1098-104.

9. Targarona EM, Balague C, Marin J, Neto RB, Martinez C, Garriga J, et al. Energy sources for laparoscopic colectomy: a prospective randomized comparison of conventional electrosurgery, bipolar computer-controlled electrosurgery and ultrasonic dissection. Operative outcome and costs analysis. Surg Innov 2005;12:339-44.

10. Hruby GW, Marruffo FC, Durak E, Collins SM, Pierorazio P, Humphrey PA, et al. Evaluation of surgical energy devices for vessel sealing and peripheral energy spread in a porcine model. J Urol 2007;178:2689-93.

11. Sankaranarayanan G, Resapu RR, Jones DB, Schwaitzberg $\mathrm{S}$, De S. Common uses and cited complications of energy in surgery. Surg Endosc 2013;27:3056-72.

12. Kennedy JS, Stranahan PL, Taylor KD, Chandler JG. Highburst-strength, feedback-controlled bipolar vessel sealing. Surg Endosc 1998;12:876-8.

13. Misra MC, Aggarwal S, Guleria S, Seenu V, Bhalla AP. Clipless and sutureless laparoscopic surgery for adrenal and extra-adrenal tumors. JSLS 2008;12:252-5.

14. Yavuz N. Laparoscopic transperitoneal adrenalectomy using the LigaSure vessel sealing system. J Laparoendosc Adv Surg Tech A 2005;15:591-5.

15. Surgit 0 . Clipless and sutureless laparoscopic adrenalectomy carried out with the LigaSure device in 32 patients. Surg Laparosc Endosc Percutan Tech 2010;20:109-13.

16. Romano F, Caprotti R, Franciosi C, De Fina S, Colombo G, Uggeri F. Laparoscopic splenectomy using ligasure: Preliminary experience. Surg Endosc 2002;16:1608-11.

17. Gelmini R, Romano F, Quaranta N, Caprotti R, Tazzioli G, Colombo $\mathrm{G}$, et al. Sutureless and stapleless laparoscopic splenectomy using radiofrequency: LigaSure device. Surg Endosc 2006;20:991-4.

* This paper was presented as a moderated poster presentation at $30^{\text {th }}$ World Congress of Endourology, 4-8 September 2012, Istanbul-Turkey. 